\title{
Macaque models of enhanced susceptibility to HIV
}

\author{
Tara R. Henning, Janet M. McNicholl, Sundaram A. Vishwanathan and Ellen N. Kersh ${ }^{*}$
}

\begin{abstract}
There are few nonhuman primate models of enhanced HIV susceptibility. Such models can improve comprehension of HIV acquisition risk factors and provide rigorous testing platforms for preclinical prevention strategies. This paper reviews past, current, and proposed research on macaque HIV acquisition risk models and identifies areas where modeling is significantly lacking. We compare different experimental approaches and provide practical considerations for designing macaque susceptibility studies. Modifiable (mucosal and systemic coinfections, hormonal contraception, and rectal lubricants) and non-modifiable (hormonal fluctuations) risk factors are highlighted. Risk acquisition models via vaginal, rectal, and penile challenge routes are discussed. There is no consensus on the best statistical model for evaluating increased susceptibility, and additional research is required. The use of enhanced susceptibility macaque models would benefit multiple facets of the HIV research field, including basic acquisition and pathogenesis studies as well as the vaccine and other biomedical preventions pipeline.
\end{abstract}

Keywords: SIV, SHIV, HIV, Susceptibility, Risk, Nonhuman primate model, Coinfection model

\section{Introduction}

The use of nonhuman primates has proven to be a critical component of modeling and understanding mechanisms of HIV acquisition as well as testing biomedical interventions to prevent infection (reviewed in [1-5]). Macaque models have helped to describe mechanics of mucosal virus acquisition $[2,6,7]$ and provide knowledge used to formulate effective prevention strategies. However, most macaque models of HIV acquisition used to develop and test biomedical HIV preventions utilize carefully controlled study arms and do not incorporate confounding experimental factors that could alter susceptibility, or infection risk. It is important to understand and consider these susceptibility-altering factors. A multitude of epidemiologic studies have highlighted coinfections, pre-existing conditions, certain behaviors, exogenous hormone use, and other factors widely found in at-risk human populations that are known or suspected to increase HIV infection risk [8-16]. In attempts to refine preclinical testing models, one could model susceptibility enhancement. Candidate preventions could then be evaluated with these models to ask whether the intervention is

\footnotetext{
* Correspondence: ekersh@cdc.gov

Division of HIV/AIDS Prevention, Centers for Disease Control and Prevention, 1600 Clifton Road NE, MS A-25, Atlanta, GA 30333, USA
}

sufficiently protective to overcome the increased susceptibility and still prevent infection. However, macaque models of enhanced susceptibility models are few, and the number of models which could then be used to rigorously test biomedical interventions in such "real-world" contexts, and possibly better inform preclinical evaluations of HIV preventions, is also limited. Moreover, such models would have useful applications apart from prevention testing, including evaluation of suspected harmful products (e.g., those hypothesized to increase HIV acquisition risk based on epidemiologic observations, in vitro testing, etc.). Potentially, the use of animal models of increased susceptibility could be used to prevent failures in large-scale human clinical trials. There have been instances, particularly in HIV vaccine research, in which susceptibility to infection is unintentionally increased (e.g., HVTN 505, STEP Trial; $[17,18])$. Thus, another benefit of an appropriate risk model could be to serve as an additional "gate keeper" of the safety of pre-clinical intervention candidates prior to advancement to clinical trials.

The paucity of risk models in macaques is a testament to the complex process of their development and study design validation. Our group has explored several experimental approaches for macaque models of enhanced susceptibility to HIV. In this review, we discuss our and 
others' approaches to the development of such models and provide strategic considerations for designing macaque susceptibility models. Focusing primarily on modifiable risk factors (as opposed to internal host factors), this review discusses nonhuman primate models of enhanced HIV susceptibility using SIV (simian immunodeficiency virus) or SHIV (simian-HIV, chimeric virus of SIV expressing HIV envelope proteins), while highlighting their scarcity and the developmental difficulties. This review is organized such that reported findings and nonhuman primate models are discussed in the context of the studies' analytical and/or design approaches. For each approach, we review the various susceptibility factors studied, models, and scientific findings and then highlight areas on which future studies might build upon and contribute to that model system of enhancement or increased infection risk or susceptibility (e.g., the ability to observe increased infections in experimental animals versus controls).

\section{Study design and statistical analysis approaches for susceptibility studies using nonhuman primate models}

The design of a susceptibility or risk enhancement study to date has generally followed one of three approaches, or perhaps even a combination thereof: repeated exposures, analyzed by a log-rank test; dose titration comparison, commonly analyzed by a form of logistic regression; or presence/absence of infection (following exposure to the proposed enhancement factor), commonly analyzed by a probability statistic, such as a chi-square or Fisher's exact test (Fig. 1). There does not seem to be a specific or bestsuited strategy for any given type or group of susceptibility enhancement factors. For example, as will be further discussed below, modeling of risk enhancement with a coinfection (e.g., malaria, schistosomiasis, HSV-2, Chlamydia trachomatis, Trichomonas vaginalis) can be achieved with any of the three aforementioned analytical approaches [19-23].

\section{Repeated low-dose exposures}

With the repeated exposures approach, a Kaplan-Meier plot (Fig. 1a) is usually constructed with the number of exposures along the $\mathrm{x}$-axis, or, with naturally cycling female pigtail macaques [23], the number of menstrual cycles during exposures. Increased susceptibility is inferred by a significant left-shifted survival curve of the experimental arm (indicated by the dotted line in Fig. 1a), relative to the control curve. Using this approach, we recently described a pigtail macaque model of SHIV acquisition risk enhancement due to sexually transmitted infection (STI) coinfection with Chlamydia trachomatis and Trichomonas vaginalis [23] (Table 1). The susceptibility study compared infection rates between nine STIpositive and seven control macaques receiving repeated low-dose $\mathrm{SHIV}_{\mathrm{SF} 162 \mathrm{p} 3}$ exposures. Because of the varying natural susceptibility during the menstrual cycle (pigtail macaques have lunar cycles, similar to humans) [24, 25], infections were analyzed by completed menstrual cycles (one menstrual cycle deemed equivalent to one SHIV susceptibility period) [23]. SHIV susceptibility was enhanced in STI-positive macaques ( $p=0.04$, log-rank), with a 2.5 times as high relative risk of infection, compared to controls (95\% CI 1.1, 5.6) [23]. A contributing factor to this enhancement is likely the increased levels of inflammatory mucosal cytokines observed during the STI inoculation and SHIV challenge phases [23].

With a repeated low-dose exposure susceptibility model, it is important to acknowledge the difficulty in determining the appropriate low virus dose when developing these models, and it is critical to identify the optimal virus dose that leaves sufficient numbers of control animals uninfected after repeated challenges. Depending on the extent of virus stock characterization (and considering also the route of challenge), determining this ideal challenge dose may require many macaques for virus titration studies prior to a susceptibility study.

\section{Dose variation}

Another option would be to compare virus dose titrations between experimental groups (e.g., with and without hypothesized enhancement factor; Fig. 1b). Using this study design, animals are first challenged with very dilute virus, and, after confirming the absence of infection, challenges continue in similar fashion with increasing concentrations of virus until an animal is infected. A benefit to this design is that, after resting, uninfected animals can be re-enrolled. However, a potential problem is that upon re-challenge of exposed animals, naturally more resistant animals may accumulate and confound results. The virus dose required to infect $50 \%$ of the animals $\left(\mathrm{AID}_{50}\right)$ is calculated for each experimental group and statistically compared, often using a form of logistic regression analysis (described in detail by Spouge and subsequently used or adapted in other studies [21, 26, 27]). Chenine, et al. used this $\mathrm{AID}_{50}$ study design to model and demonstrate enhanced susceptibility to SHIV infection due to systemic helminth coinfection with Schistosoma mansoni [21]. Chenine, et al. [28] and Ayash-Raskovsky, et al. [20] first alluded to potential risk enhancement by reporting that schistosomiasis both reactivates SHIV and increases viral replication rates. The subsequent susceptibility study in rhesus macaques used intrarectal challenges with varying doses of a SHIV Clade C infectious molecular clone [29] (Table 1). The infecting virus dose was 17-fold lower in $S$. mansoni-infected animals, compared to controls [21] $(p<0.001$, logistic regression methods of Spouge [26]). The authors described possible mechanisms for increased susceptibility by showing higher concentrations of viral target cells in $S$. mansoni-infected macaques and 


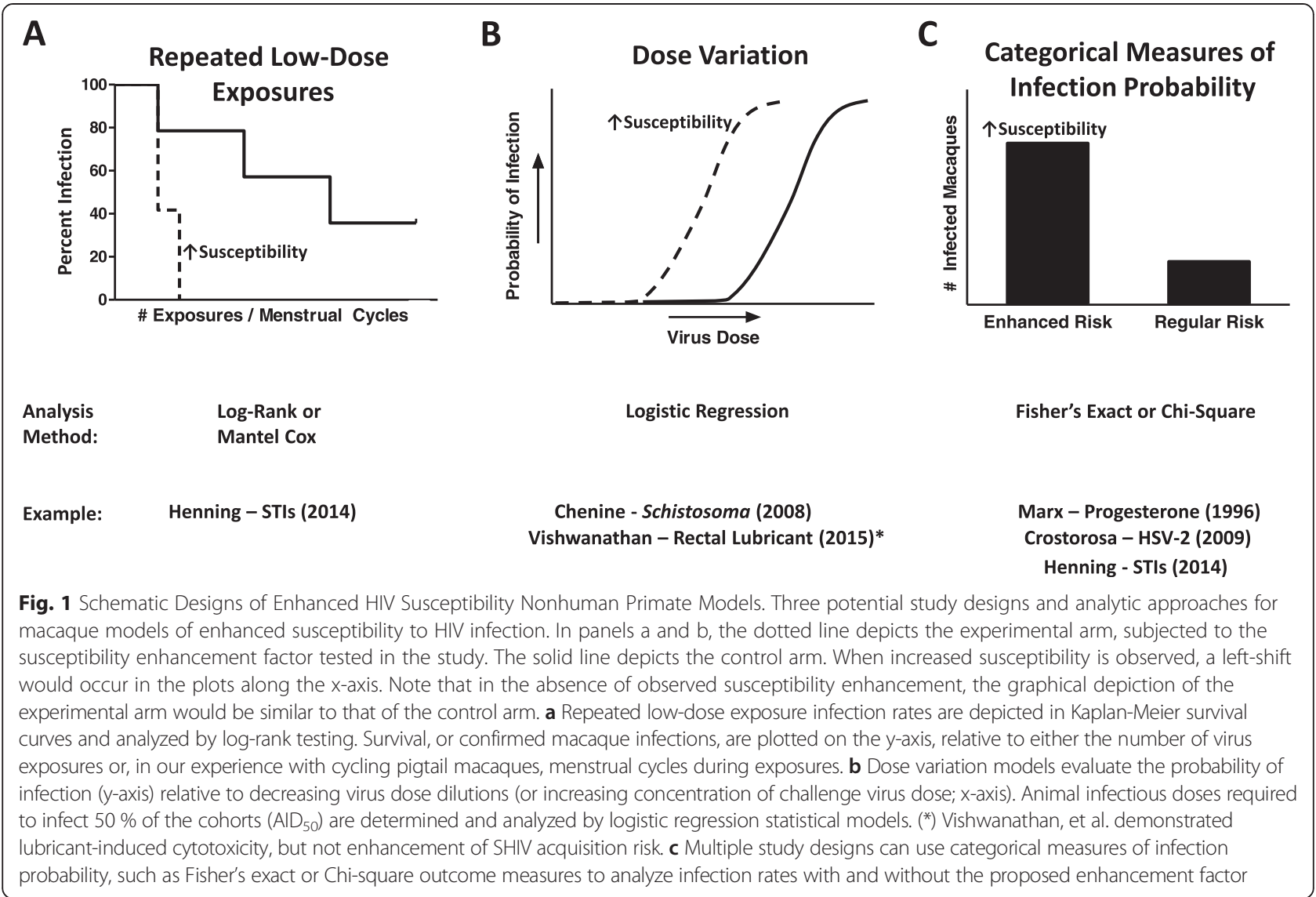

higher levels of viral replication in these cellular subsets [21]. To address whether the increased risk was due to mucosal inflammation and/or subsequent target cell recruitment, or if systemic effects of schistosomiasis increased SHIV infection risk, a follow-up risk study was performed again using a virus titration study design, except, in this study, macaques were challenged intravenously [30] (Table 1). In this subsequent study, the AID $_{50}$ and peak virus level between $S$. mansoni-infected and control groups were not significantly different, suggesting susceptibility is facilitated by the helminth's interaction at the mucosa, resultant inflammation, and/or the consequent upregulation of viral replication at the mucosal surfaces [30].

In an HIV vaccine model using rhesus macaques, Qureshi, et al. also used a dose escalation model [31] (Table 1) to determine if a nonhuman primate model could recapitulate the enhanced susceptibility to HIV infection seen in the human phase III STEP trial [17, 31]. In the trial, preexisting seropositivity to adenovirus serotype 5 (Ad5) was associated with increased HIV-1 infections in men who received an Ad5 HIV vaccine. In the macaque model, escalating doses of SIVmac251 were given through repeated penile exposures to animals infected with adenovirus and then vaccinated with an Ad5
SIV vaccine [31]. In this model, an enhanced SIV infection rate was observed in animals with pre-existing Ad5 immunity that received low doses $\left(10^{3}\right.$ TCID $\left.{ }_{50}\right)$ of SIV, but not higher doses. The analytic approaches supporting this finding included log-rank tests of survival, determination of relative risks of infection and likelihood-ratios in statistical models with an assumption of a leaky vaccine effect. Moreover, when examining the difference in the number of infections in the nonhuman primate and human models, the enhancement was marginal in both, but of a similar order of magnitude (two in 43 macaques, compared to 16 in approximately 1800 men). These important findings demonstrate that macaque models can be used to determine if biomedical preventions increase susceptibility to SIV.

Our group has also employed the use of virus dose titration challenges to evaluate the effect of rectal lubricants on rectal SHIV acquisition risk [27] (Table 1). This study was first conceptualized after recent in vitro and ex vivo studies reported detrimental effects of lubricants on rectal and genital epithelium [32-34]. The cytotoxicity phase of the study showed acute effects of a highly hyperosmolar lubricant on macaque anorectal tissues [27]. Because of the overt susceptibility factors (local inflammatory response, rectal bleeding, epithelial sloughing), a 
Table 1 Literature Review of Macaque Models of Enhanced HIV Risk

\begin{tabular}{|c|c|c|c|c|c|c|}
\hline $\begin{array}{l}\text { Studied factor } \\
\text { of susceptibility } \\
\text { enhancement }\end{array}$ & $\begin{array}{l}\text { Observed } \\
\text { } s u s c e p t i b i l i t y / \\
\text { infection risk }\end{array}$ & $\begin{array}{l}\text { Discussion of enhancement/ } \\
\text { mechanism or potential } \\
\text { susceptibility factor }\end{array}$ & $\begin{array}{l}\text { Macaque } \\
\text { gender/species }\end{array}$ & Virus stock/challenge dose & Study design parameters & References \\
\hline \multicolumn{7}{|c|}{ Behavioral Factors of Susceptibility Enhancement } \\
\hline \multirow[t]{3}{*}{ Chronic Alcohol Use } & \multirow[t]{3}{*}{ No } & \multirow{3}{*}{$\begin{array}{l}\text { Multiple, potential susceptibility factors: } \\
\text { shifts in genital flora, increases in } \\
\text { memory CD4+ T cells (viral targets), } \\
\text { decreases in CD8+ T cells (anti-viral); } \\
\text { १viremia in treated animals }\end{array}$} & \multirow{3}{*}{$\begin{array}{l}\text { Male and } \\
\text { Female Rhesus }\end{array}$} & \multirow[t]{3}{*}{$\mathrm{n} / \mathrm{a}$} & \multirow{3}{*}{$\begin{array}{l}\text { Designs vary; alcohol steadily } \\
\text { administered via jacketed device }\end{array}$} & Loganantharaj (2014) [40] $]^{a}$ \\
\hline & & & & & & Poonia (2006; AIDS) [22] \\
\hline & & & & & & Poonia ([41]; JAIDS) (2006) \\
\hline Rectal Lubricant Use & No & $\begin{array}{l}\text { Acute cytotoxicity observed after } \\
\text { application of tested lubricant, but } \\
\text { no } \uparrow \text { in risk during challenge phase }\end{array}$ & $\begin{array}{l}\text { Male and Female } \\
\text { Cynomologus }\end{array}$ & $\mathrm{SHIV}_{\mathrm{SF} 162 \mathrm{p} 3}$ (varying doses) & $\begin{array}{l}\text { Intrarectal challenge route; } \\
\text { AID }_{50} \text { dose titration model }\end{array}$ & Vishwanathan (2015) [27] \\
\hline \multicolumn{7}{|c|}{ Coinfections as Factor of Susceptibility Enhancement } \\
\hline $\begin{array}{l}\text { C. trachomatis/T. vaginal } \\
\text { Coinfection (Genital } \\
\text { Tract Infection) }\end{array}$ & Yes & $\begin{array}{l}2.5 \text {-fold } \uparrow \text { risk in STI-positive animals; } \\
\text { STI-positive animals infected in fewer } \\
\text { menstrual cycles, compared to controls } \\
\text { ( } p=0.04 \text {, log-rank; } p=0.02 \text {, Fisher's exact). } \\
\text { Increases in mucosal pro-inflammatory } \\
\text { cytokines during STI inoculation and } \\
\text { SHIV challenge periods }\end{array}$ & Female Pigtail & $\mathrm{SHIV}_{\mathrm{SF} 162 \mathrm{p} 3}\left(10 \mathrm{TCID}_{50}\right)$ & $\begin{array}{l}\text { Intravaginal challenge route; } \\
\text { repeat low-dose exposures; } \\
\text { exposures per menstrual } \\
\text { cycle for risk assessment }\end{array}$ & Henning (2014) [23] \\
\hline \multirow{2}{*}{$\begin{array}{l}\text { HSV-2 Coinfection } \\
\text { (Genital Tract Infection) }\end{array}$} & \multirow[t]{2}{*}{ Yes } & \multirow{2}{*}{$\begin{array}{l}\text { Transmission not linked to active } \\
\text { lesions. Possible HSV-2-induced } \\
\text { immunosuppression impairs anti-SHIV } \\
\text { response; subsequent study }{ }^{b} \text { reported } \\
\text { HSV-2 increases concentration of } \\
\text { a4 } 37^{\text {high }} \text { CD4+ T cells (viral targets) }\end{array}$} & \multirow[t]{2}{*}{ Female Rhesus } & \multirow{2}{*}{$\begin{array}{l}\text { SHIV-RT (200 and } 10^{3} \\
\left.\text { TCID }_{50}\right) \uparrow \text { Risk with } 10^{3}\end{array}$} & \multirow{2}{*}{$\begin{array}{l}\text { Intravaginal challenge route; } \\
\text { animals either treated } 1 \times \text { or } \\
2 \times \text { with DMPA, then either } \\
200 \text { or } 10^{3} \mathrm{TCID}_{50}\end{array}$} & Crostarosa (2009) [22] \\
\hline & & & & & & Martinelli [36] ${ }^{\mathrm{b}}$ (2011) \\
\hline Malaria (Systemic Infection) & No & $\begin{array}{l}\text { Evidence of potential susceptibility } \\
\text { factors } ; \uparrow \text { viral load and CCR5+ CD4+ } \\
T \text { cells (viral targets) in } P \text {. fragile-infected } \\
\text { animals, but risk/hazard ratio } \\
\text { not determined }\end{array}$ & Male Rhesus & SIVmac239 $\left(10^{3} \mathrm{TCID}_{50}\right)$ & $\begin{array}{l}\text { Intravenous challenge route, } \\
\text { comparing control and } \\
\text { coinfected groups }\end{array}$ & Trott (2011) [48] ${ }^{\mathrm{a}}$ \\
\hline $\begin{array}{l}\text { Schistosomiasis } \\
\text { (Helminth/Systemic Infection) }\end{array}$ & Yes & $\begin{array}{l}\text { 17-fold lower dose of virus required } \\
\text { to infect } S \text {. mansoni-infected animals; } \\
\uparrow \text { viremia and replication in CD4+ } \\
\text { central memory cells (viral targets) }\end{array}$ & Female Rhesus & $\begin{array}{l}\text { SHIV-1 157ipd3N4 } \\
\text { (Clade C; varying doses) }\end{array}$ & $\begin{array}{l}\text { Intrarectal challenge route; } \\
\text { AID }_{50} \text { dose titration model }\end{array}$ & Chenine (2008) [21] \\
\hline $\begin{array}{l}\text { Schistosomiasis } \\
\text { (Helminth/Systemic Infection) }\end{array}$ & No & $\begin{array}{l}\text { Intravenous challenges (compared to } \\
\text { mucosal challenges) did not result in } \\
\text { same increase of SHIV acquisition risk }\end{array}$ & Female Rhesus & $\begin{array}{l}\text { SHIV-1 157ipd3N4 } \\
\text { (Clade C; varying doses) }\end{array}$ & $\begin{array}{l}\text { Intravenous challenge route; } \\
\text { AlD }_{50} \text { dose titration model }\end{array}$ & Siddappa (2011) [30] \\
\hline \multicolumn{7}{|c|}{ Hormonal Factors of Susceptibility Enhancement } \\
\hline \multirow{2}{*}{$\begin{array}{l}\text { Hormone Levels Associated } \\
\text { with Menstrual Cycle Phase } \\
\text { (Endogenous Hormone) }\end{array}$} & \multirow[t]{2}{*}{ Yes $^{c}$} & \multirow{2}{*}{$\begin{array}{l}\text { Exact mechanisms to be determined. } \\
\text { Increased rates of SHIV RNA detection } \\
\text { in late-luteal and menses phases }\end{array}$} & \multirow[t]{2}{*}{ Female Pigtail } & \multirow[t]{2}{*}{$\mathrm{SHIV}_{\mathrm{SF} 162 \mathrm{p3}}\left(50 \mathrm{TCID}_{50}\right)$} & \multirow{2}{*}{$\begin{array}{l}\text { Intravaginal challenge route; } \\
\text { repeat low-dose exposures }\end{array}$} & Vishwanathan (2011) [25] $]^{\mathrm{a}}$ \\
\hline & & & & & & Kersh (2014) [24] ${ }^{a}$ \\
\hline
\end{tabular}

with Menstrual Cycle Phase

Increased rates of SHIV RNA detection
in late-luteal and menses phases 
Table 1 Literature Review of Macaque Models of Enhanced HIV Risk (Continued)

\begin{tabular}{|c|c|c|c|c|c|c|}
\hline Phase of Menstrual Cycle & No & $\begin{array}{l}\text { Vaginal application of cell-free virus } \\
\text { resulted in infection; } 50 \% \text { of } \\
\text { macaques infected in luteal phase, } \\
\text { compared to } 24 \% \text { challenged } \\
\text { in follicular phase } \\
\text { (not statistically significant) }\end{array}$ & Female Rhesus & 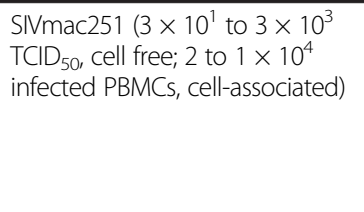 & $\begin{array}{l}\text { Compared infectivity of } \\
\text { different doses of cell-free } \\
\text { vs. cell-associated virus via } \\
\text { intravaginal vs. intravenous } \\
\text { inoculation routes }\end{array}$ & Sodora (1998) [39] \\
\hline $\begin{array}{l}\text { Progesterone Implants } \\
\text { (Exogenous Hormone) }\end{array}$ & Yes & $\begin{array}{l}\text { 7.7-fold } \uparrow \text { risk in implanted animals. } \\
\text { DMPA induced significant vaginal } \\
\text { thinning, with } \uparrow \text { peak and 1st } \\
3 \text { months of viremia }\end{array}$ & Female Rhesus & SIVmac251 (640 TCID $\left.{ }_{50}\right)$ & $\begin{array}{l}\text { Single intravaginal challenge } \\
\text { with determined "minimal } \\
\text { vaginal dose" }\end{array}$ & Marx (1996) [35] \\
\hline $\begin{array}{l}\text { Ad5 } 5^{d} \text { Vaccine (Vaccine- } \\
\text { induced enhancement) }\end{array}$ & Yes & $\begin{array}{l}\uparrow \text { risk in } \mathrm{Ad} 5 \text { seropositive animals } \\
\text { infected with the lower }\left(10^{3} \mathrm{TCID}_{50}\right) \\
\text { challenge dose; study recapitulates } \\
\text { lack of Ad5 vaccine efficacy and } \\
\text { model vaccine-induced acquisition } \\
\text { risk enhancement }\end{array}$ & Male Rhesus & SIVmac251 (varying doses) & $\begin{array}{l}\text { Penile challenge route; } 10 \text {-fold } \\
\text { increases in virus concentration } \\
\left(10^{3} \text { to } 10^{5}\right) \text {; comparisons among } \\
\text { groups }+/- \text { Ad5 immunity, SIV } \\
\text { vaccination, and naïve controls }\end{array}$ & Qureshi (2012) [31] \\
\hline
\end{tabular}

Relevant literature is grouped by type of susceptibility enhancement factor, with description of study design, parameters, and analytical approach and effect(s) of enhancement factor(s)

Terminology of 'increased infections in experimental animals over controls' and 'increased ( $\uparrow$ ) risk/susceptibility' is synonymous with observed enhancement of SIV/SHIV infection susceptibility due to or attributed to the studied (potential) enhancement factor

${ }^{a}$ Citations describe studies not reporting or not designed to demonstrate enhanced susceptibility, but describe potential or key susceptibility factors for HIV/SIV/SHIV infection

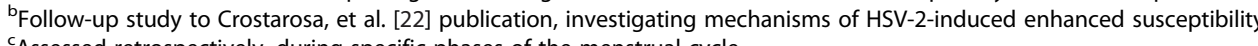

CAssessed retrospectively, during specific phases of the menstrual cycle

Ad5 - Adenovirus, serotype 5 
susceptibility phase was conducted employing the $\operatorname{AID}_{50}$ study design. Despite the acute cytotoxicity, the difference in SHIV $_{\text {SF162p3 }}$ doses required to infect controls versus lubricant-treated animals was not statistically different. While this particular study did not report increased risk, it is prudent to note that despite plausible mechanistic data, models may not identify increased susceptibility or be sufficiently sensitive to demonstrate modest increases in susceptibility. Vishwanathan, et al. discussed that possibly the acute nature or type of induced inflammation was not sufficient to increase infection risk to levels above the 2-fold theoretical threshold limit with the virus dose-titration challenge model, or perhaps the highly regenerative nature of the rectal mucosa negates inflammatory effects of lubricant application [27]. Of note, follow-up studies in rhesus macaques will use a repeat low-dose design (instead of $\mathrm{AID}_{50}$ ) as an alternate model to further evaluate possible risk enhancement due to rectal lubricant use.

\section{Categorical measures of infection probability}

The use of a probability analysis, such chi-square or Fisher's exact measures (Fig. 1c) can be applied to a variety of study designs, including repeat low-dose and dose titration models. This direct comparison considers the relationship between infection (with the challenge virus) and the nominal, or categorical, variables of the presence/absence of the proposed enhancement factor. Fisher's exact test is often more appropriate than a chisquare analysis because of the smaller sample sizes necessitated in nonhuman primate research. As with the repeated exposure model, selecting the appropriate virus dose is also an important factor when designing susceptibility challenge studies with Fisher's exact analyses. The use of too high a dose will result in all animals becoming infected and loss of the ability to observe enhancement between experimental groups.

While studying the effects of progesterone implants in macaques, Marx, et. al, provided one of the first descriptions of Depo-Provera's, or depot medroxyprogesterone acetate (DMPA), effect on susceptibility to SIV acquisition and used Fisher's exact analyses to demonstrate increased SIV risk due to exogenous hormone use [35] (Table 1). In this study, using an analytical approach depicted in Fig. 1c, female rhesus macaques received subcutaneous implants of progesterone-containing pellets, while the control group received placebo implants. After vaginal challenge with SIVmac251, cell-associated SIV was detected in $78 \%$ of DMPA-treated animals, but only $10 \%$ of controls ( $p<0.008$, Fisher's exact), 7.7 times the risk [35].

Crostarosa, et al. developed a vaginal herpes simplex virus type-2 (HSV-2) coinfection model in female rhesus macaques and used the model to evaluate susceptibility to vaginal infection with SHIV-RT [22] (Table 1). They employed a complex study design which also factored the role of DMPA on susceptibility, though direct or statistically significant conclusions were not made on the effect of the exogenous hormone on susceptibility. Overall, using an approach similar to Fig. 1c, conclusions were drawn from $n=28$ macaques and $n=46$ macaque infections/challenges in which macaques remaining SHIV-RT-negative were reused in subsequent arms. HSV-2-positive animals which received only one hormone injection showed increased susceptibility to SHIVRT infection at $10^{3} \mathrm{TCID}_{50}(100 \%$ infection), relative to HSV-2-negative controls which also received one DepoProvera dose ( $46 \%$ infection) ( $p<0.05$, Fisher's exact) [22]. This model was then used to elucidate mechanisms of the enhanced susceptibility, such as increased dendritic cell availability as a viral target cell and immunomodulation of viral replication [36], and to provide a more stringent model system for evaluating efficacy of non-nucleoside reverse transcriptase inhibitor (NNRTI)containing microbicides [22, 37] (Table 1).

In our C. trachomatis-T. vaginalis coinfection study, we corroborated log-rank analyses of enhanced risk with Fisher's exact testing [23]. By evaluating the number of menstrual cycles with and without SHIV infection among the two experimental groups, STI coinfection was once again associated with increased risk of vaginal HIV acquisition ( $p=0.02$; [23]) (Table 1$)$. This report is an example of how a multi-statistic approach can be used to analyze (and potentially strengthen) observations of enhanced susceptibility.

\section{Observations on infection susceptibility from varying study designs}

While the focus of this review has been on research using nonhuman primate models of HIV susceptibility, it is still prudent to acknowledge the wealth of other studies in macaques providing evidence of important and relevant susceptibility factors, albeit not in the framework of a susceptibility-virus challenge study. For example, it has been speculated that HIV susceptibility varies throughout the menstrual cycle in humans [38], as demonstrated in macaques challenged with $\mathrm{S}(\mathrm{H}) \mathrm{IV}$ $[24,25,39]$. Sodora, et al. first described the propensity for greater rates of infection in the luteal versus follicular phase of the menstrual cycle in rhesus macaques [39]. Our group addressed the same topic through retrospective studies in female pigtail macaques by analyzing time points of first plasma $\mathrm{SHIV}_{\mathrm{SF} 162 \mathrm{p} 3}$ RNA detection from repeat low-dose intravaginal challenge studies relative to the phase of the menstrual cycle [24, 25] (Table 1). The majority of infections were detected in the follicular phase, with imputed infection dates (after correcting for a viral eclipse period) in either the menstrual or premenstrual phases $[24,25]$. While these studies were not 
prospectively designed to model increased risk per se $[24,25,39]$, they demonstrate varying and enhanced susceptibility to $\mathrm{S}(\mathrm{H}) \mathrm{IV}$ infection during certain phases of the menstrual cycle.

Evidence of susceptibility factors relating to modifiable behavioral risk factors have also been reported from macaque models of chronic alcohol consumption. Chronic alcohol usage induces adverse shifts in cellular and microbial populations in the genital tract, increases concentrations of viral target cells, gut memory CD4+ $\mathrm{T}$ cells, reduces levels of cytolytic T cells, and, in SIVinfected animals, was associated with higher levels of viremia [40-42] (Table 1). From human studies, there is empirical evidence for the likelihood of HIV risk enhancement by other substances, such as cocaine; however, macaque models have not yet been developed to further investigate this factor [43]. Related to alcohol consumption, further exploration of susceptibility models which also evaluate the role of gut $\mathrm{T}$ regulatory and Th17 cells would benefit the field. As these and other CD4+ cell populations are known to mitigate host response to the virus, control viral activation and spread, and play a key role in disease progression, macaque susceptibility enhancement models incorporating the further study of their role in resistance and susceptibility to infection could prove critical for HIV prevention efforts [44-47].

In addition to helminth infections, other systemic infections, such as malaria, have been modeled in nonhuman primates through which evidence of increased SIV risk was observed. Rhesus macaques coinfected with Plasmodium fragile had significantly higher ramp-up levels of plasma viremia and increased concentrations of CCR5 + CD4 + T cells (SIV target cells). The study showed evidence of increased susceptibility but did not specifically evaluate relative risk or hazard ratios [48] (Table 1). Studies such as these provide impetus for the development of additional nonhuman primate susceptibility models and execution of susceptibility-virus challenge studies designed to examine the effect of these factors on virus acquisition, potentially using an approach discussed in this review.

\section{Discussion}

This review discusses study design strategies and reported models of enhanced susceptibility using the framework of three statistical approaches. The field of nonhuman primate models for HIV acquisition, pathogenesis, and efficacy testing of prevention methods is comprehensive, with detailed literature and a great depth of understanding of how these models can be applied and how the generated data should be interpreted. In comparison, there is a paucity of nonhuman primate models for assessing susceptibility to HIV (using SIV/SHIV) and for evaluating factors that might increase the risk of virus acquisition. And these relatively few studies also underscore the difficulty in developing efficient (e.g., small animal numbers, streamlined design), relevant (e.g., effect size, applicability to the epidemic), and reliable (e.g., low $p$ values, narrow confidence intervals) nonhuman primate model systems to examine increased susceptibility. Developing and establishing such studies may require large numbers of animals, with multiple study arms to fine-tune study design (for example, the Crostarosa, et al. study used a total of 28 macaques [22] and Qureshi, et al. used 43). The studies described here also provide insight into factors enhancing, or with the potential to enhance, susceptibility to HIV (or SIV/SHIV) infection. When designing models of enhanced susceptibility, one is also faced with the appropriate selection of relevant factors or a reliable study design approach to best represent the epidemic. For example, what is the most relevant genital tract pathogen or form of hormonal contraception to use? Even the basic question of virus stock selection can have great bearing on study outcome, relevance to the epidemic, and the nature of the experimental question(s) [49]. The repeat low-dose model has been successfully used in efficacy studies [50-54], but perhaps a virus dose-titration $\left(\mathrm{AID}_{50}\right)$ model might provide greater power to detect increases in risk. The ability to anticipate the magnitude of risk from epidemiologic or in vitro studies could inform model selection. The logrank or dose escalation approach may provide greater power in evaluating acquisition risk in the lower ranges of magnitude, or modest risk enhancement, whereas Fisher's exact testing is perhaps more appropriate in analyzing higher magnitudes of susceptibility enhancement. It is possible that the most relevant and robust model system utilizes a combination of study design approaches described herein. For example, Qureshi, et al. elegantly described the use of multiple analytical strategies in their Ad5 vaccine enhancement study [31]. Even when acquisition risk is anticipated as marginal, it is possible that the appropriate selection of challenge route, virus titer and statistical approach can still capture the extent of the risk enhancement.

We've highlighted three possible, and previously described [21, 23, 27, 31, 35] study design and statistical analytical approaches, but readily acknowledge that this field of research is limited and that future models and study designs could, and perhaps should, be developed to better address the question of increased HIV susceptibility. It is possible that a novel system altogether would be most appropriate for conducting susceptibility studies. Ideally, a side-by-side comparison of these varying study design approaches would be conducted, testing the performance of a factor known to enhance infection risk (e.g. STIs, DMPA) in each model system. Such an experiment, albeit resource intensive, would provide a well-controlled comparison of the various modeling strategies and statistical analyses. 
Nonhuman primate studies incorporating enhanced susceptibility models are capable of supporting epidemiologic findings of HIV risk, defining susceptibility mechanisms or factors, and identifying targets for focused interventions. Moreover, models of enhanced susceptibility provide a system with which biomedical preventions can be rigorously tested in the context of "real-world" susceptibility conditions, prior to proceeding to complex and costly human clinical trials. As previously mentioned, the use of an increased risk model to test candidate clinical trial prevention strategies could alert us to possible susceptibility enhancement, prior to the introduction in humans. One could argue the paucity of such models is a hindrance to the advancement of broadly efficacious HIV prevention strategies. The field of HIV prevention research still doesn't have the "perfect" model of HIV acquisition, a goal that may indeed be unattainable. Nonetheless, efforts to refine our models may necessitate a combination of varying study designs for differing genders, infection routes and cofactors. Continued work in the development and use of nonhuman primate models of enhanced susceptibility could, or would, increase our understanding of acquisition and provide better models for prevention testing.

\begin{abstract}
Abbreviations
Ad5: Adenovirus, serotype 5; $A_{1 D_{50}}$ : Animal infectious dose required to infect $50 \%$ of cohort; DMPA: Depot medroxyprogesterone acetate; HIV: Human immunodeficiency virus; HSV-2: Herpes simplex virus, type 2; HVTN-005: HIV (human immunodeficiency virus) vaccine trials network, clinical trial number 505; NNRTI: Non-nucleoside reverse transcriptase inhibitor; PBMC: Peripheral blood mononuclear cells; RNA: Ribonucleic acid; SHIV: Simian-human (chimeric) immunodeficiency virus; SIV: Simian immunodeficiency virus; SHIV-RT: Simian-human (chimeric) immunodeficiency virus, expressing human immunodeficiency virus reverse transcriptase enzyme; STEP (trial): Not an acronym; represents a Merck-sponsored human immunodeficiency virus vaccine trial, also known as HVTN (human immunodeficiency virus vaccine trials network) 502; STI: Sexually transmitted infection(s); $\mathrm{TCID}_{50}$ : Tissue culture infectious dose required to infection $50 \%$ of tested samples/cohort.
\end{abstract}

\section{Competing interests}

The authors declare that they have no competing interests.

\section{Authors' contributions}

TRH was primarily responsible for preparing the manuscript, in collaboration with ENK. JMM and SAV provided literature referencing support and editorial guidance. All authors read and approved the final manuscript.

\section{Acknowledgements}

The authors thank Katherine Butler, Dr. Walid Heneine, and Dr. Angela Amedee for insightful comments during the preparation of this manuscript. Funded by CDC and partially by an interagency agreement (Y1-A1-0681-02) between $\mathrm{CDC}$ and $\mathrm{NIH}$. The findings and conclusions in this report are those of the authors and do not necessarily represent the views of the Centers for Disease Control and Prevention.

Received: 23 April 2015 Accepted: 3 June 2015

Published online: 14 June 2015

\section{References}

1. Evans DT, Silvestri G. Nonhuman primate models in AIDS research. Curr Opin HIV AIDS. 2013;8:255-61.

2. Fennessey CM, Keele BF. Using nonhuman primates to model HIV transmission. Curr Opin HIV AIDS. 2013;8:280-7.
3. Garcia-Lerma JG, Heneine W. Animal models of antiretroviral prophylaxis for HIV prevention. Curr Opin HIV AIDS. 2012;7:505-13.

4. Haynes BF, McElrath MJ. Progress in HIV-1 vaccine development. Curr Opin HIV AIDS. 2013;8:326-32.

5. Veazey RS. Animal models for microbicide safety and efficacy testing. Curr Opin HIV AIDS. 2013:8:295-303.

6. Keele BF, Li H, Learn GH, Hraber P, Giorgi EE, Grayson T, et al. Low-dose rectal inoculation of rhesus macaques by SIVsmE660 or SIVmac251 recapitulates human mucosal infection by HIV-1. J Exp Med. 2009;206:1117-34.

7. Stone M, Keele BF, Ma ZM, Bailes E, Dutra J, Hahn BH, et al. A limited number of simian immunodeficiency virus (SIV) env variants are transmitted to rhesus macaques vaginally inoculated with SIVmac251. J Virol. 2010;84:7083-95.

8. Baggaley RF, White RG, Hollingsworth TD, Boily MC. Heterosexual HIV-1 infectiousness and antiretroviral use: systematic review of prospective studies of discordant couples. Epidemiology. 2013;24:110-21.

9. Cohen MS. Sexually transmitted diseases enhance HIV transmission: no longer a hypothesis. Lancet. 1998;351 Suppl 3:5-7.

10. Division of HIV/AIDS Prevention. Who's at risk for HIV? Atlanta, GA: Centers for Disease Control and Prevention; 2014.

11. Finlayson TJ, Le B, Smith A, Bowles K, Cribbin M, Miles I, et al. HIV risk, prevention, and testing behaviors among men who have sex with men-National HIV Behavioral Surveillance System, 21 U.S. cities, United States, 2008. Morb Mort Wkly Rep Surveill Summ. 2011;60:1-34.

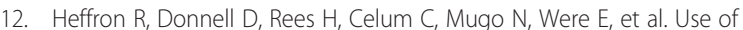
hormonal contraceptives and risk of HIV-1 transmission: a prospective cohort study. Lancet Infect Dis. 2012;12:19-26.

13. Hughes JP, Baeten JM, Lingappa JR, Magaret AS, Wald A, de Bruyn G, et al. Determinants of per-coital-act HIV-1 infectivity among African HIV-1-serodiscordant couples. J Infect Dis. 2012;205:358-65.

14. Kapiga SH, Sam NE, Bang H, Ni Q, Ao TT, Kiwelu I, et al. The role of herpes simplex virus type 2 and other genital infections in the acquisition of HIV-1 among high-risk women in northern Tanzania. J Infect Dis. 2007;195:1260-9.

15. Laga M, Manoka A, Kivuvu M, Malele B, Tuliza M, Nzila N, et al. Non-ulcerative sexually transmitted diseases as risk factors for HIV-1 transmission in women: results from a cohort study. AIDS. 1993;7:95-102.

16. Mishra S, Steen R, Gerbase A, Lo YR, Boily MC. Impact of high-risk sex and focused interventions in heterosexual HIV epidemics: a systematic review of mathematical models. PloS One. 2012;7:e50691.

17. Buchbinder SP, Mehrotra DV, Duerr A, Fitzgerald DW, Mogg R, Li D, et al, Efficacy assessment of a cell-mediated immunity HIV-1 vaccine (the Step Study): a double-blind, randomised, placebo-controlled, test-of-concept trial. Lancet. 2008;372:1881-93.

18. Hammer SM, Sobieszczyk ME, Janes H, Karuna ST, Mulligan MJ, Grove D, et al. Efficacy trial of a DNA/rAd5 HIV-1 preventive vaccine. N Engl J Med. 2013;369:2083-92.

19. Abu-Raddad L, Patnaik P, Kublin JG. Dual infection with HIV and malaria fuels the spread of both diseases in sub-Saharan Africa. Science. 2006;314:1603-6.

20. Ayash-Rashkovsky M, Chenine AL, Steele LN, Lee SJ, Song R, Ong H, et al Coinfection with Schistosoma mansoni reactivates viremia in rhesus macaques with chronic simian-human immunodeficiency virus clade C infection. Infect Immun. 2007;75:1751-6.

21. Chenine AL, Shai-Kobiler E, Steele LN, Ong H, Augostini P, Song R, et al. Acute Schistosoma mansoni infection increases susceptibility to systemic SHIV clade $C$ infection in rhesus macaques after mucosal virus exposure. PLoS Negl Trop Dis. 2008;2:e265.

22. Crostarosa F, Aravantinou M, Akpogheneta OJ, Jasny E, Shaw A, Kenney J, et al. A macaque model to study vaginal HSV-2/immunodeficiency virus co-infection and the impact of HSV-2 on microbicide efficacy. PLoS One. 2009;4:e8060.

23. Henning TR, Butler K, Hanson D, Sturdevant G, Ellis S, Sweeney EM, et al. Increased susceptibility to vaginal simian/human immunodeficiency virus transmission in pig-tailed macaques coinfected with Chlamydia trachomatis and Trichomonas vaginalis. J Infect Dis. 2014;210(8):1239-47.

24. Kersh EN, Tara H, Ajay Vishwanathan S, Hansen D, Morris M, Butler K, et al. SHIV Susceptibility Changes During the Menstrual Cycle of Pigtail Macaques. J Med Primatol. 2014;43:310-6.

25. Vishwanathan SA, Guenthner PC, Lin CY, Dobard C, Sharma S, Adams DR, et al. High susceptibility to repeated, low-dose, vaginal SHIV exposure late in the luteal phase of the menstrual cycle of pigtail macaques. J Acquir Immune Defic Syndr. 2011;57:261-4. 
26. Spouge JL. Statistical analysis of sparse infection data and its implications for retroviral treatment trials in primates. Proc Natl Acad Sci U S A. 1992;89:7581-5.

27. Vishwanathan SA, Morris MR, Wolitski RJ, Luo W, Rose C, Blau DM, et al. Rectal application of a highly osmolar personal lubricant in a macaque model induces acute cytotoxicity but does not increase risk of SHIV infection. PLoS One. 2015;10(4):e0120021.

28. Chenine AL, Buckley KA, Li PL, Rasmussen RA, Ong H, Jiang S, et al. Schistosoma mansoni infection promotes SHIV clade $C$ replication in rhesus macaques. AIDS. 2005;19:1793-7.

29. Song RJ, Chenine AL, Rasmussen RA, Ruprecht CR, Mirshahidi S, Grisson RD, et al. Molecularly cloned SHIV-1157ipd3N4: a highly replication- competent, mucosally transmissible R5 simian-human immunodeficiency virus encoding HIV clade C Env. J Virol. 2006;80:8729-38.

30. Siddappa NB, Hemashettar G, Shanmuganathan V, Semenya AA, Sweeney ED, Paul KS, et al. Schistosoma mansoni enhances host susceptibility to mucosal but not intravenous challenge by R5 Clade C SHIV. PLoS Negl Trop Dis. 2011;5:e1270.

31. Qureshi H, Ma ZM, Huang Y, Hodge G, Thomas MA, DiPasquale J, et al Low-dose penile SIVmac251 exposure of rhesus macaques infected with adenovirus type 5 (Ad5) and then immunized with a replication-defective Ad5-based SIV gag/pol/nef vaccine recapitulates the results of the phase IIb step trial of a similar HIV-1 vaccine. J Virol. 2012;86:2239-50.

32. Adriaens E, Remon JP. Mucosal irritation potential of personal lubricants relates to product osmolality as detected by the slug mucosal irritation assay. Sex Transm Dis. 2008;35:512-6.

33. Begay O, Jean-Pierre N, Abraham CJ, Chudolij A, Seidor S, Rodriguez A, et al. Identification of personal lubricants that can cause rectal epithelial cell damage and enhance HIV type 1 replication in vitro. AIDS Res Hum Retroviruses. 2011;27:1019-24.

34. Dezzutti CS, Brown ER, Moncla B, Russo J, Cost M, Wang L, et al. Is wetter better? An evaluation of over-the-counter personal lubricants for safety and anti-HIV-1 activity. PLoS One. 2012;7:e48328.

35. Marx PA, Spira Al, Gettie A, Dailey PJ, Veazey RS, Lackner AA, et al. Progesterone implants enhance SIV vaginal transmission and early virus load. Nat Med. 1996:2:1084-9.

36. Martinelli $E$, Tharinger $H$, Frank I, Arthos J, Piatak Jr M, Lifson JD, et al. HSV-2 infection of dendritic cells amplifies a highly susceptible HIV-1 cell target. PLoS Pathog. 2011;7:e1002109.

37. Hsu M, Aravantinou M, Menon R, Seidor S, Goldman D, Kenney J, et al. A combination microbicide gel protects macaques against vaginal simian human immunodeficiency virus-reverse transcriptase infection, but only partially reduces herpes simplex virus- 2 infection after a single high-dose cochallenge. AIDS Res Hum Retroviruses. 2014;30(2):174-83.

38. Wira CR, Fahey JV. A new strategy to understand how HIV infects women: identification of a window of vulnerability during the menstrual cycle. AIDS. 2008:22:1909-17.

39. Sodora DL, Gettie A, Miller CJ, Marx PA. Vaginal transmission of SIV: assessing infectivity and hormonal influences in macaques inoculated with cell-free and cell-associated viral stocks. AIDS Res Hum Retroviruses. 1998;14 Suppl 1:S119-23.

40. Loganantharaj N, Nichols WA, Bagby GJ, Volaufova J, Dufour J, Martin DH, et al. The Effects of Chronic Binge Alcohol on the Genital Microenvironment of SIV-Infected Female Rhesus Macaques. AIDS Res Hum Retroviruses. 2014;30:783-91.

41. Poonia B, Nelson S, Bagby GJ, Veazey RS. Intestinal lymphocyte subsets and turnover are affected by chronic alcohol consumption: implications for SIV/HIV infection. J Acquir Immune Defic Syndr. 2006;41:537-47.

42. Poonia B, Nelson S, Bagby GJ, Zhang P, Quniton L, Veazey RS. Chronic alcohol consumption results in higher simian immunodeficiency virus replication in mucosally inoculated rhesus macaques. AIDS Res Hum Retroviruses. 2006;22:589-94.

43. Kim SG, Jung JB, Dixit D, Rovner Jr R, Zack JA, Baldwin GC, et al. Cocaine exposure enhances permissiveness of quiescent T cells to HIV infection. J Leukoc Biol. 2013;94:835-43.

44. Hartigan-O'Connor DJ, Hirao LA, McCune JM, Dandekar S. Th17 cells and regulatory $T$ cells in elite control over HIV and SIV. Curr Opin HIV AIDS. 2011;6:221-7.

45. Pallikkuth S, Micci L, Ende ZS, Iriele Rl, Cervasi B, Lawson B, et al. Maintenance of intestinal Th17 cells and reduced microbial translocation in
SIV-infected rhesus macaques treated with interleukin (IL)-21. PLoS Pathog. 2013;9:e1003471.

46. Pereira LE, Villinger F, Onlamoon N, Bryan P, Cardona A, Pattanapanysat K, et al. Simian immunodeficiency virus (SIV) infection influences the level and function of regulatory T cells in SIV-infected rhesus macaques but not SIV-infected sooty mangabeys. J Virol. 2007;81:4445-56.

47. Byrareddy SN, Kallam B, Arthos J, Cicala C, Nawaz F, Hiatt J, et al. Targeting alpha4beta7 integrin reduces mucosal transmission of simian immunodeficiency virus and protects gut-associated lymphoid tissue from infection. Nat Med. 2014;20:1397-400.

48. Trott KA, Chau JY, Hudgens MG, Fine J, Mfalila CK, Tarara RP, et al. Evidence for an increased risk of transmission of simian immunodeficiency virus and malaria in a rhesus macaque coinfection model. J Virol. 2011;85:11655-63.

49. von Bubnoff A. Looking for the Perfect Challenge. In: IAVI Report: The Publication on AIDS Vaccine Research. 2009.

50. Dobard C, Sharma S, Martin A, Pau CP, Holder A, Kuklenyik Z, et al. Durable protection from vaginal simian-human immunodeficiency virus infection in macaques by tenofovir gel and its relationship to drug levels in tissue. J Virol. 2012:86:718-25.

51. Dobard C, Sharma S, Parikh UM, West R, Taylor A, Martin A, et al. Postexposure protection of macaques from Vaginal SHIV infection by topical integrase inhibitors. Sci Transl Med. 2014;6:227ra35.

52. Parikh UM, Dobard C, Sharma S, Cong ME, Jia H, Martin A, et al. Complete protection from repeated vaginal simian-human immunodeficiency virus exposures in macaques by a topical gel containing tenofovir alone or with emtricitabine. J Virol. 2009;83:10358-65.

53. Radzio J, Aung W, Holder A, Martin A, Sweeney E, Mitchell J, et al. Prevention of vaginal SHIV transmission in macaques by a coitallydependent Truvada regimen. PloS One. 2012;7:e50632.

54. Smith JM, Rastogi R, Teller RS, Srinivasan P, Mesquita PM, Nagaraja U, et al. Intravaginal ring eluting tenofovir disoproxil fumarate completely protects macaques from multiple vaginal simian-HIV challenges. Proc Natl Acad Sci U S A. 2013;110:16145-50.

\section{Submit your next manuscript to BioMed Central and take full advantage of:}

- Convenient online submission

- Thorough peer review

- No space constraints or color figure charges

- Immediate publication on acceptance

- Inclusion in PubMed, CAS, Scopus and Google Scholar

- Research which is freely available for redistribution 